ESSAY REVIEW

\title{
A History of the (Attempted) Institutionalization of Parapsychology
}

\begin{abstract}
Okkultismus im Gehäuse. Institutionalisierungen der Parapsychologie im 20 Jahrhundert im internationalen Vergleich [Occultism in Housings. Institutionalizing Parapsychology in the 2oth Century, an International Comparison] edited by Anna Lux and Sylvia Paletschek. Walter de Gruyter, 2016. 433 pp. ISBN 9783-11-046376-7.
\end{abstract}

\section{Reviewed by Michael Nahm}

Institute for Frontier Areas of Psychology and Mental Health (IGPP), Freiburg, Germany nahm@igpp.de

https://10.31275/20201861

Creative Commons License CC-BY-NC

In addition to an introduction, the book contains 14 chapters. Most of them represent elaborated text versions of contributions that were presented by the authors at a (nearly) eponymous conference held in Freiburg, Germany, on October 17, 2014. As the book title announces, the chapter authors trace the development of parapsychological research in different countries. Usually they focus on the more or usually less successful attempts to academicize and institutionalize parapsychology as a legitimate scientific discipline, but sometimes they also cover related aspects. The chapters include historical parapsychological treatises for Germany (Ulrich Linse, Anna Lux, Uwe Schellinger, Martin Schneider, Bernd Wedemeyer-Kolwe) including the German Democractic Republic (GDR; East Germany) (Andreas Anton, Ina Schmied-Knittel, Michael Schetsche), France (Renaud Evrard), Great Britain (Elizabeth Valentine), Hungary (Júlia Gyimesi), The Netherlands (Ingrid Kloosterman), Russia in the Soviet and post-Soviet periods/areas (Birgit Menzel), and the US (Eberhard Bauer, Anna Lux). The four chapters covering France, Great 
Britain, Hungary, and The Netherlands are written in English, the others in German. In the following, I will briefly touch upon the topics I found most interesting.

Anna Lux from the University in Freiburg, Germany, identified several characteristic aspects of academic parapsychological work in Germany and compared them with those in the US, which took place at about the same time and were more strongly focused on the experimental paradigm. She shows how different social circumstances and also private predilections of the main actors involved resulted in different developments. This also applies to the fate of parapsychology in the other countries mentioned, which is surprisingly multifaceted: While in The Netherlands the situation with official professorships at the University of Utrecht can be compared most closely to that of Germany where Hans Bender (1907-1991) held a professorship at the University of Freiburg, the academization of parapsychology in Hungary was hindered by an influential spiritualist and religious social current. In France, however, comparable efforts were mainly impeded by continued opposition of established scientists. Even so, the private research facility Institute Métapsychique International (IMI) was founded in France in 1919, and has survived to this day despite adverse circumstances. Great Britain has always played a special role in Western parapsychology, mainly due to the foundation of the Society for Psychical Research as early as 1882, which is still considered an international figurehead for a constructive and critical examination of parapsychological topics. However, in Great Britain there existed several other societies and "institutes," which were often small and short-lived. It was not until 1985 that parapsychological research was able to gain a foothold at a British university for the first time through an endowed professorship in Edinburgh, held by Robert Morris (1942-2004) until 2004. From there, numerous graduates were able to carry on the work of parapsychological research questions at other universities.

A comparison between parapsychology-oriented activities in the Soviet area and in the former GDR is particularly interesting. As much as the practices and ideological positions of their relevant state organs were nominally similar, they differed in the question of how to deal with parapsychological phenomena. In the USSR, as in the US, a pronounced interest in research into "extrasensory" communication 
methods was cultivated for decades, whereby the official handling of this topic oscillated in a remarkable way between strict prohibition and research promotion. In many cases, military objectives were pursued, but application-related scientific interests in potentially useful types of radiation played a role as well. Of course, Russian scientists had to move within the Marxist-Leninist worldview-occult and esoteric notions had to be avoided. The extent to which this research has been carried out is surprising. Birgit Menzel from the university in Mainz, Germany, writes:

Parapsychological research has always been carried out more or less intensively in the Soviet period up to the post-Soviet present. This research took place in an almost uncountable number of institutions of the most diverse disciplines, with and without official support, with and without financial means, open and secret, isolated as well as networked. But their status has always been precarious. (p. 149; my translation)

Menzel highlighted that a bibliography of Russian papers on parapsychological research from 1993 contains more than 700 titles, including 237 publications on bilocation and bioenergetic information, 172 on telepathy, 58 on poltergeist phenomena, and 33 on telekinesis. One of the most important institutions for the development of parapsychological skills in the military sector was apparently a "Department 1003," which existed from 1986 to 2003 and had an annual budget of four million dollars until 1998, plus personnel costs. Its end was apparently due to a new phase of a state-institutional blockade that began in the early zooos. However, interest in anomalistic phenomena among the Russian population seems to remain unbroken.

Yet, the situation in the GDR was very different: Here, the government insisted strictly on "scientifically" founded dialectical materialism: Parapsychological phenomena cannot occur in a materialistic world, and consequently potential occupations with parapsychology were monitored by the state and nipped in the bud. Every utterance in support of psi-phenomena from especially West Germany was claimed to be based on superstition, deception, and even deliberate manipulation of the population by the capitalist ruling class. The question of why the parapsychological research of the GDR's big 


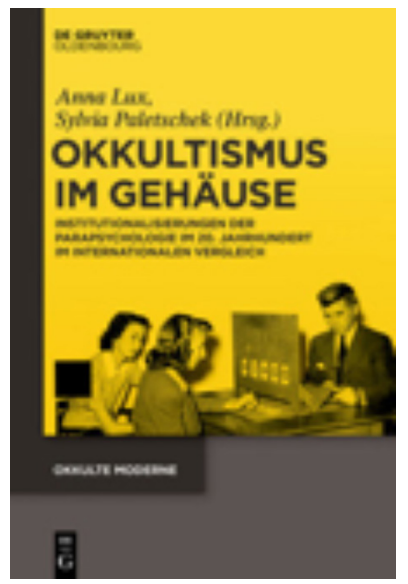

brother USSR remained practically unknown and uncommented on in the GDR remains unanswered for the time being.

Uwe Schellinger from the Institute for Frontier Areas of Psychology and Mental Health (IGPP) in Freiburg, Germany, gives an overview of the attempts made in Germany to integrate paranormal knowledge into police investigations (known as "criminal telepathy"). Even at times when such practices were highly unwelcome, they were occasionally still resorted to by officialswhen the pressure to do so was great enough. For example, psychics who had previously been persecuted and imprisoned in concentration camps by the Nazis were recruited in 1943 to locate the whereabouts of the abducted Benito Mussolini (1883-1945).

In the final chapter, Eberhard Bauer, who has worked at the Freiburg IGPP since 1970, is interviewed by Anna Lux and the ethnologist Ehler Voss about his experiences as a professional parapsychologist. The chapter therefore offers valuable personal insights of an actor who speaks from within the housings of institutional parapsychology, and doesn't just illuminate it from the outside.

In sum, the present volume is highly recommendable, providing a solid understanding of the complex background and developments in parapsychology on national and international fronts in the 2oth century. But finally, I would like to add some thoughts that this book, being a historical treatise, elicited. I find it curious that virtually dozens of historical and sociocultural treatises about parapsychology, occultism, spiritualism, mediumship, etc., have been published during recent years by scientists situated in academic settings. It would be interesting to count the major treatises from authors at universities versus practicing parapsychologists at universities, and to compare this relationship to other science disciplines. Admittedly, each research discipline needs history to be properly understood, and some historical treatises about hitherto little-known topics, such as those covered in 
chapters of the present volume, are of considerable interest and value. Sometimes, certain arguments also offer further-reaching lines of thought. One might ask, for example: Is it likely that in all the decades during which Russians funded and pursued parapsychological studies they never documented a single, genuine psi event? Usually, however, historical books about parapsychology, including this volume, are written from a safe distance and with no commitment to take seriously the collected evidence for parapsychological phenomena from an ontological perspective, or to advance practical research.

Nevertheless, active parapsychologists, who provided and who continue to provide the material for all these historical studies, are currently still struggling to establish their research in academic circles, as the present book clearly demonstrates. Unfortunately, it seems that parapsychologists are increasingly being regarded as career study objects for others, like a peculiar and endangered animal species. But whereas endangered animal species often profit from studies that aim at providing a better understanding of their life history, whereabouts, structural habitats, and ecological niches, parapsychologists hardly profit from such studies. This development contains a somewhat strange aftertaste, which is probably also felt by Eberhard Bauer, who commented critically on the growing number of speakers "from the second row" in his interview (p. 396, my translation). 